\title{
Improvement of the Homogeneous Fenton Reaction for Degradation of Methylene Blue and Acid Orange II
}

\author{
Fumihiko Ogata, ${ }^{a}$ Takehiro Nakamura, ${ }^{a}$ and Naohito Kawasaki*,a,b \\ ${ }^{a}$ Faculty of Pharmacy, Kindai University; 3-4-1 Kowakae, Higashi-Osaka, Osaka 577-8502, Japan: and ${ }^{b}$ Antiaging \\ Center, Kindai University; 3-4-1 Kowakae, Higashi-Osaka, Osaka 577-8502, Japan. \\ Received February 7, 2018; accepted March 2, 2018
}

In this study, the degradation of methylene blue (MB) and acid orange II (ORII) by the Fenton reaction was improved by using $\mathrm{HCl}$ and $\mathrm{HNO}_{3}$. In addition, the effects of $\mathrm{pH}$, temperature, concentration of Fenton's reagent, and adjustment reagent of solution $\mathrm{pH}$ on the decoloration were evaluated. The results showed that the optimal $\mathrm{pH}$ for decoloration of $\mathrm{MB}$ and ORII was 2.5 and that the decoloration of MB and ORII increased with higher temperature and concentration of Fenton's reagent. Moreover, the decoloration in the Fenton-reaction process with $\mathrm{HCl}$ and $\mathrm{HNO}_{3}$ was greater than the decoloration with $\mathrm{H}_{2} \mathrm{SO}_{4}$ by approximately 4.3-5.6 and 1.7-5.6 times for $\mathrm{MB}$ and 3.2-3.6 and 4.6-7.2 times for ORII compared to with $\mathrm{H}_{2} \mathrm{SO}_{4}$. These results indicated that Fenton-reaction with $\mathrm{HCl}$ and $\mathrm{HNO}_{3}$ could be useful for the degradation technology of dyes compared to generally Fenton-reactions.

Key words Fenton reaction; methylene blue; acid orange II; degradation

Water pollution due to dyes is a serious problem in developed countries. The removal of dyes from wastewater is a challenge to relevant industries because the dyes used in the field are stable compounds that are difficult to decompose by common water treatments. ${ }^{1)}$ Methylene blue (MB) is a cationic dye used extensively for dyeing and printing cotton, silk, and other materials. It is also used as a medicinal dye because of its antiseptic properties. ${ }^{2}$ In addition, the discharge of the anionic dye acid orange II (ORII) into the water stream is undesirable because of its color and also because of its toxicity, non-biodegradability, and potential carcinogenic characteristics. $^{3,4)}$ Therefore, the removal of MB and ORII from wastewater has attracted attention worldwide.

Oxidation with Fenton's reagent, based on ferrous ion and hydrogen peroxide, is a proven and effective technology for the destruction of a large number of hazardous and organic pollutants. ${ }^{5)}$ Sulfuric acid (or sodium hydroxide) has often been used for adjustment of solution $\mathrm{pH}$ in the Fenton-reaction process. However, there are no reports of other acidic solutions being used for adjustment of solution $\mathrm{pH}$. In recent years, heterogeneous Fenton reactions have been developed by many researchers. However, the efficiency of wastewater treatment with many heterogeneous Fenton reactions is not satisfactory because the heterogeneous Fenton reaction is costly and requires the use of energy, such as ultraviolet light or ultrasonic energy, to promote the reaction. ${ }^{6,7)}$ In addition, hydroxyl radicals generated by the Fenton reaction are easily affected by electrolytes in solution. Thus, if the general (homogeneous) Fenton reaction could be improved with a simple treatment, the value and applicability of the Fenton reaction for the purification of wastewater including dyes would increase substantially.

The objective of the present study was to demonstrate the feasibility of the Fenton oxidation process with changed parameters for the degradation of dye and also investigate the optimal operating conditions for MB and ORII degradation.

\section{Experimental}

Materials $\mathrm{MB}$ and ORII were purchased from Wako Pure Chemical Industries, Ltd. (Osaka, Japan) and Tokyo Chemical Industry Co., Ltd. (Tokyo, Japan), respectively. Sulfuric acid, hydrochloric acid, nitric acid, sodium hydroxide, iron (II) sulfate heptahydrate, and hydrogen peroxide (30\%) were also purchased from Wako Pure Chemical Industries, Ltd.

Effect of pH on Decoloration of $\mathrm{MB}$ and ORII Dye solutions (MB and ORII, $50 \mathrm{~mL}$ ) were prepared at a concentration of $50 \mathrm{mg} / \mathrm{L}$ and iron(II) sulfate heptahydrate and hydrogen peroxide $(30 \%)$ were simultaneously added to each dye solution (dye: $\mathrm{Fe}^{2+}: \mathrm{H}_{2} \mathrm{O}_{2}$ molar ratios of $1.0: 0.13: 1.5$, $1.0: 0.25: 3.0,1.0: 0.50: 6.0$, and $1.0: 2.0: 24$, respectively). Subsequently, the sample solutions were shaken at $100 \mathrm{rpm}$ for $20 \mathrm{~h}$ at $25^{\circ} \mathrm{C}$. The $\mathrm{pH}$ of the sample solution was adjusted by sulfuric acid or sodium hydroxide $(\mathrm{pH} 1.0,2.5,6.0$, and 8.0, respectively). The sample solutions were filtered through a $0.45 \mu \mathrm{m}$ membrane filter and the filtrate was analyzed with a spectrophotometer (UV-1200, Shimadzu Co., Ltd., Kyoto, Japan). The absorption wavelengths used for MB and ORII were 655 and $485 \mathrm{~nm}$, respectively. The decoloration percentage was calculated using Eq. 1:

$$
P=\left(C_{0}-C_{\mathrm{e}}\right) / C_{0} \times 100
$$

where $P$ is the decoloration percentage (\%), $C_{0}$ is the concentration before degradation $(\mathrm{mg} / \mathrm{L})$, and $C_{\mathrm{e}}$ is the concentration after degradation $(\mathrm{mg} / \mathrm{L})$.

The $\mathrm{pH}$ of the solution was measured using a digital $\mathrm{pH}$ meter (Seven Easy, Mettler Toledo, Kyoto, Japan). In the range of $0.1-10 \mathrm{mg} / \mathrm{L}$ of $\mathrm{MB}$ and ORII, the absorbance at 655 and $485 \mathrm{~nm}$ of the dye versus the concentration plot showed excellent linearity $(r>0.998)$. We confirmed that the adsorption wavelength did not change at different $\mathrm{pH}$ conditions (before and after Fenton reaction) in preliminary experiment.

Effect of Temperature on Decoloration of MB and ORII Dye solutions (MB and ORII, $50 \mathrm{~mL}$ ) were prepared at a concentration of $50 \mathrm{mg} / \mathrm{L}$, and iron(II) sulfate heptahydrate and 
hydrogen peroxide $(30 \%)$ were simultaneously added to each dye solution (dye: $\mathrm{Fe}^{2+}: \mathrm{H}_{2} \mathrm{O}_{2}$ molar ratios of $1.0: 0.13: 1.5$, $1.0: 0.25: 3.0$, and $1.0: 0.50: 6.0$, respectively). Subsequently, the sample solutions were shaken at $100 \mathrm{rpm}$ for $20 \mathrm{~h}$ at 1,25 , and $50^{\circ} \mathrm{C}$. The $\mathrm{pH}$ of each sample solution was adjusted by sulfuric acid ( $\mathrm{pH}$ 2.5). The decoloration percentage was calculated using Eq. 1. In addition, total organic carbon (TC) was measured using a TOC-500 analyzer (Shimadzu Co., Ltd.).

Effects of Sulfuric Acid, Hydrochloric Acid, and Nitric Acid on Adjustment of Solution pH Dye solutions (MB and ORII, $50 \mathrm{~mL}$ ) were prepared at a concentration of $50 \mathrm{mg} / \mathrm{L}$, and iron(II) sulfate heptahydrate and hydrogen peroxide $(30 \%)$ were simultaneously added to each dye solution (dye: $\mathrm{Fe}^{2+}: \mathrm{H}_{2} \mathrm{O}_{2}$ molar ratios and other conditions were the same as in section 2.3). The sample solution was adjusted by sulfuric acid, hydrochloric acid, or nitric acid ( $\mathrm{pH}$ 1.0). The decoloration percentage was calculated using Eq. 1.

\section{Results and Discussion}

Effect of $\mathbf{p H}$ on Decoloration of $\mathrm{MB}$ and ORII The decoloration percentages are shown in Fig. 1. The optimal $\mathrm{pH}$
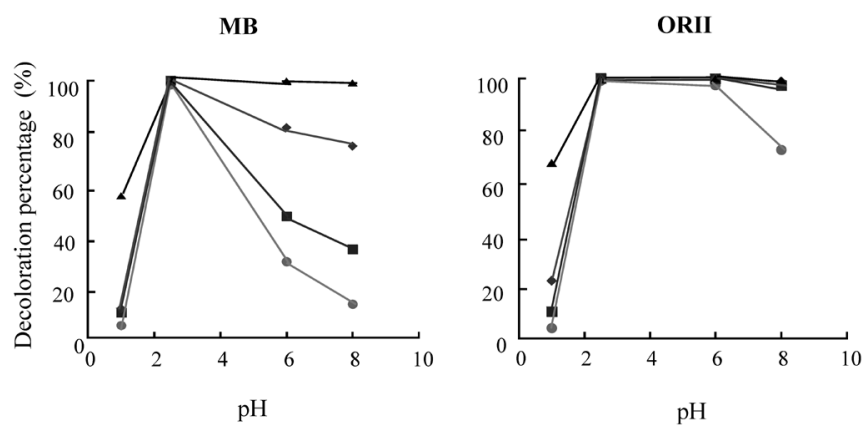

Fig. 1. Effect of $\mathrm{pH}$ on the Decoloration of Dyes

Initial concentration: $50 \mathrm{mg} / \mathrm{L}$, solution volume: $50 \mathrm{~mL}$, temperature: $25^{\circ} \mathrm{C}$, agitation speed: $100 \mathrm{rpm}$, contact time: $20 \mathrm{~h}, \mathrm{pH}: 1-8$. Dye: $\mathrm{Fe}^{2+}: \mathrm{H}_{2} \mathrm{O}_{2}$ molar ratio of $1.0: 0.13: 1.5(\circlearrowleft), 1.0: 0.25: 3.0(\boldsymbol{\square}), 1.0: 0.50: 6.0(\bullet)$, and $1.0: 2.0: 24(\boldsymbol{\Delta})$, respectively. for decoloration of MB and ORII was 2.5 (decomposition percentage of $100 \%$ ). Other $\mathrm{pH}$ conditions were not suitable for decoloration. The decoloration of MB and ORII was greater at higher concentration of Fenton's reagent. The traditionally accepted Fenton mechanism has been represented by many researchers. Equation 2 depicts the Fenton reaction, which implies oxidation of ferrous iron to ferric iron to decompose $\mathrm{H}_{2} \mathrm{O}_{2}$ into hydroxyl radicals. ${ }^{8}$ ) Subsequently, the ferric ions generated can be reduced by reaction with hydrogen peroxide, as shown in Eq. 3. This reaction is called the Fenton like reaction in an effective cyclic mechanism.

$$
\begin{gathered}
\mathrm{Fe}^{2+}+\mathrm{H}_{2} \mathrm{O}_{2} \rightarrow \mathrm{Fe}^{3+}+\mathrm{OH}^{-}+\mathrm{OH} \\
\mathrm{Fe}^{3+}+\mathrm{H}_{2} \mathrm{O}_{2} \rightarrow \mathrm{Fe}^{2+}+\mathrm{HO}_{2}+\mathrm{H}^{+}
\end{gathered}
$$

It is clear that $\mathrm{OH}$ radicals are the active species in the $\mathrm{MB}$ and ORII degradation processes. The degradation pathways of $\mathrm{MB}$ and ORII by the Fenton reaction have been reported by previous studies. $\mathrm{MB}$ is degraded to azure $\mathrm{B}$, azure $\mathrm{A}$, azure $\mathrm{C}$, thionin, and finally phenothiazine. ${ }^{9)}$ Moreover, the degradation process of ORII is initiated by the cleaving of the $\mathrm{C}-\mathrm{N}$ bond due to the oxidative attack of hydroxyl radicals, which leads to the formation of 2-naphtol and 4-hydrazinobenzenesulfonic acid. The intermediate compounds then can be oxidized further, causing their rings to open, and finally mineralized into $\mathrm{CO}_{2}$ and $\mathrm{H}_{2} \mathrm{O}$, ${ }^{3,10,11)}$ We were able to confirm the decoloration of $\mathrm{MB}$ and ORII in the Fenton-reaction process (Fig. 2). The decomposition of MB and ORII in the more acidic condition (at $\mathrm{pH} 1.0$ ) was lower than that at $\mathrm{pH} 2.5$ (decomposition percentage of MB and ORII of 4.0-59.5 and $2.2-68.8 \%$, respectively), indicating that the higher concentration of $\mathrm{H}^{+}$results in the prevention of regeneration of the ferrous ion. In addition, iron complex species $\left[\mathrm{Fe}\left(\mathrm{H}_{2} \mathrm{O}\right)_{6}\right]^{2+}$ exist at very low $\mathrm{pH}$ values, and these species react more slowly with hydrogen peroxide than other species. ${ }^{12)}$ The decomposition of MB and ORII at $\mathrm{pH} 6.0$ and 8.0 was also lower than the decomposition at $\mathrm{pH} 2.5$. Firstly, the reactivity of $\mathrm{Fe}^{2+}$ was lower at the higher $\mathrm{pH}$ values. Secondly, autolysis of hydrogen

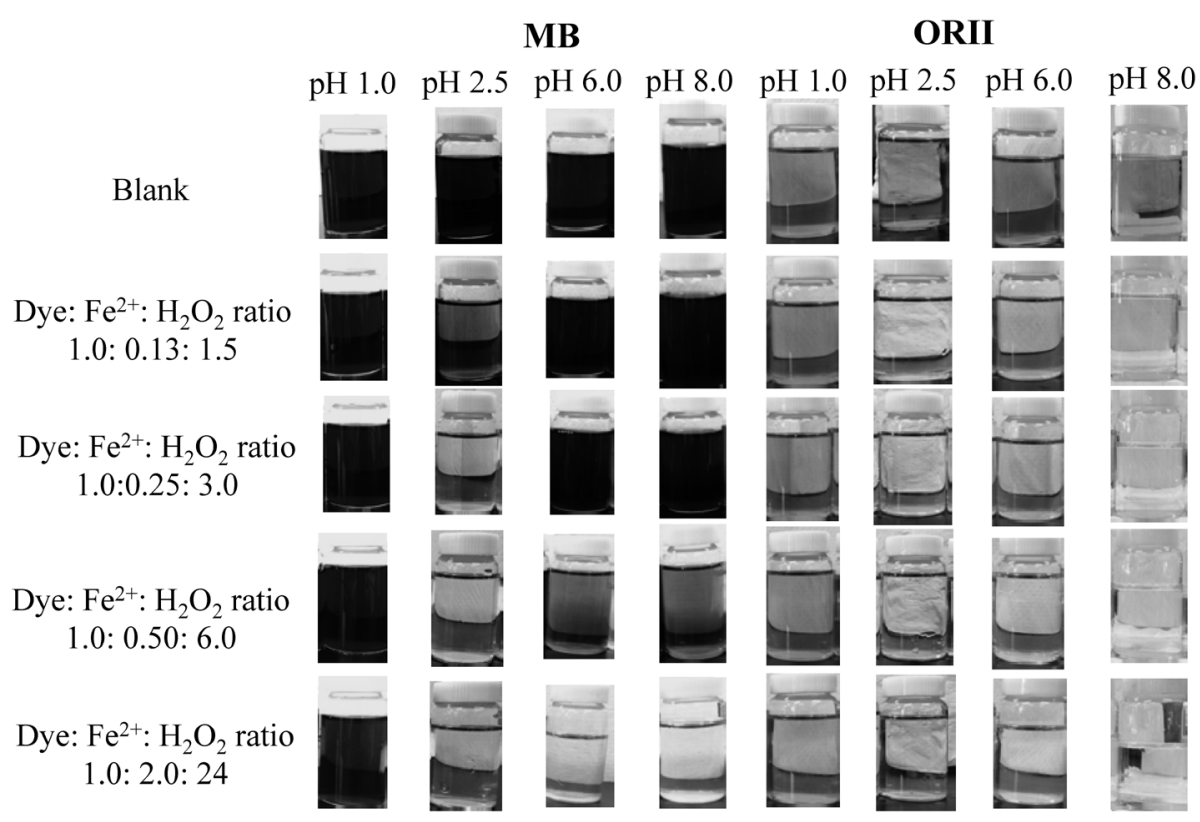

Fig. 2. Changes in Dyes before and after Fenton Reaction 


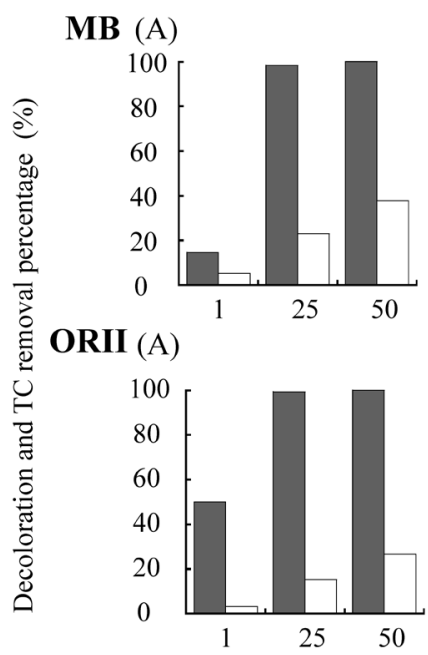

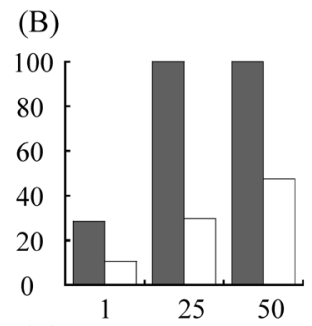

(B)

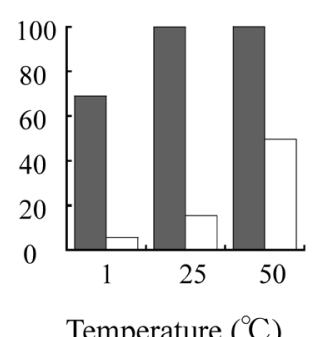

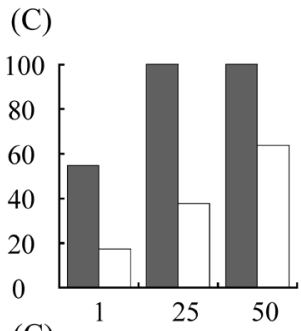

(C)

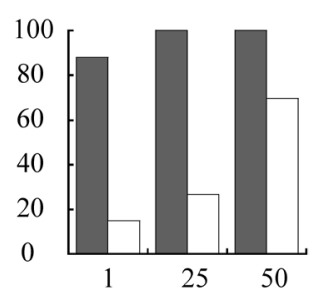

Fig. 3. Effect of Temperature on the Decoloration of Dyes

Initial concentration: $50 \mathrm{mg} / \mathrm{L}$, solution volume: $50 \mathrm{~mL}$, temperature: $25^{\circ} \mathrm{C}$, agitation speed: $100 \mathrm{rpm}, \mathrm{contact}$ time: $20 \mathrm{~h}$, $\mathrm{pH}: 2.5$. Dye: $\mathrm{Fe}^{2+}: \mathrm{H}_{2} \mathrm{O}_{2}$ molar ratio of $1.0: 0.13: 1.5(\mathrm{~A}), 1.0: 0.25: 3.0(\mathrm{~B})$, and $1.0: 0.50: 6.0(\mathrm{C})$. $\square$ Dye, $\square$ TC.

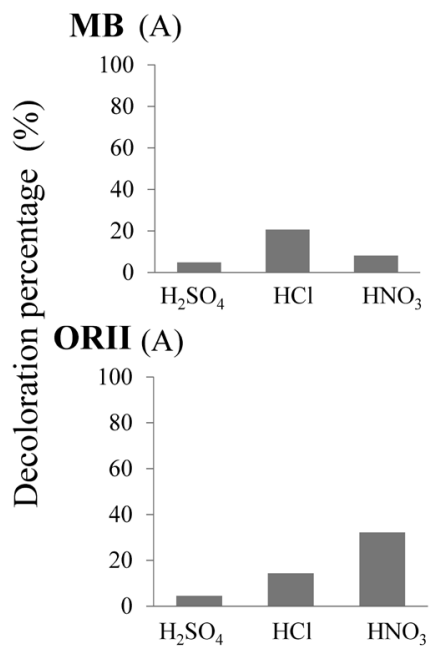

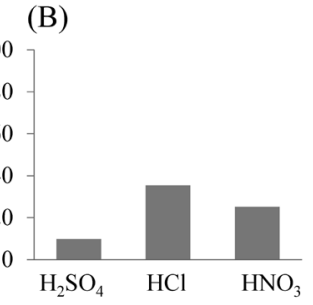

(B)

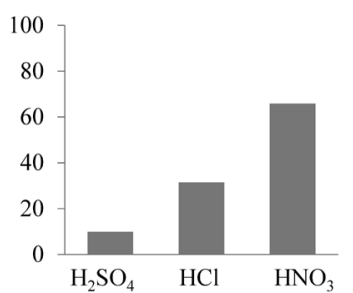

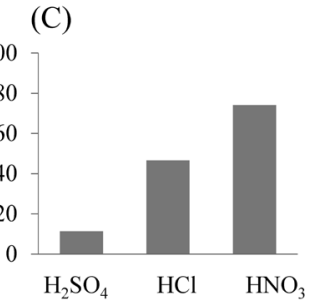

(C)

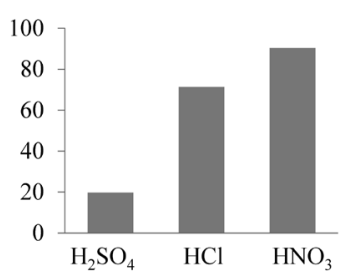

Fig. 4. Effect of Acidic Solution on the Decoloration of Dyes

Initial concentration: $50 \mathrm{mg} / \mathrm{L}$, solution volume: $50 \mathrm{~mL}$, temperature: $25^{\circ} \mathrm{C}$, agitation speed: $100 \mathrm{rpm}$, contact time: $20 \mathrm{~h}, \mathrm{pH}: 1.0$. Dye: Fe ${ }^{2+}: \mathrm{H}_{2} \mathrm{O}_{2}$ molar ratio of $1.0: 0.13: 1.5$ (A), $1.0: 0.25: 3.0(\mathrm{~B})$, and $1.0: 0.50: 6.0(\mathrm{C})$.

peroxide occurred. Previous study has shown that hydrogen peroxide is decomposed easily in the presence of heavy metals $\left(\mathrm{Cu}, \mathrm{Fe}, \mathrm{Cr}, \mathrm{Mn}\right.$, etc.) in the basic condition (Eqs. 4 and 5). ${ }^{13)}$

$$
\begin{gathered}
\mathrm{H}_{2} \mathrm{O}_{2}+\mathrm{OH}^{-} \rightarrow \mathrm{H}_{2} \mathrm{O}+\mathrm{HO}_{2}^{-} \\
2 \mathrm{HO}_{2}^{-} \rightarrow 2 \mathrm{HO}^{-}+\mathrm{O}_{2}
\end{gathered}
$$

In addition, $\mathrm{Fe}^{3+}$ was not reduced in the basic condition and $\mathrm{Fe}_{2} \mathrm{O}_{3}$ precipitated (Eq. 6), suggesting that the Fenton reaction and the Fenton like reaction did not occur smoothly.

$$
2 \mathrm{Fe}^{3+}+6 \mathrm{OH}^{-}+(n-3) \mathrm{H}_{2} \mathrm{O} \rightarrow \mathrm{Fe}_{2} \mathrm{O}_{3} \cdot n \mathrm{H}_{2} \mathrm{O}
$$

However, the decomposition of MB and ORII with excess concentration of Fenton's reagent was faster than the abovementioned reactions (Eqs. 4-6). Differences in the decomposition of MB and ORII were attributed to differences in their molecular structures.
Effect of Temperature on Decoloration of MB and ORII Figure 3 shows the effect of temperature on the decoloration of MB and ORII. Decomposition of the dyes increased with increasing temperature (decoloration percentage was $100 \%$ at 25 and $50^{\circ} \mathrm{C}$ ). A previous study reported that a substantial increase in the extent of degradation of MB was observed when the reaction temperature was raised from 8 to $26^{\circ} \mathrm{C}^{5)}$ Similar trends were observed in this experimental condition. However, in the previous study, further increase in the reaction temperature from 26 to $40^{\circ} \mathrm{C}$ resulted in a decrease in the extent of degradation of $\mathrm{MB} .^{5)}$ On the other hand, we could not confirm a decrease in the extent of degradation of MB and ORII in this experimental condition. The experimental condition of the previous study (dye: $\mathrm{Fe}^{2+}: \mathrm{H}_{2} \mathrm{O}_{2}$ molar ratio of $1.0: 1.14: 14.1$ ) was harsher than the experimental condition of this study. The differences in the results were not elucidated, but increasing the temperature did not affect the decomposition of hydrogen peroxide; it did increase the thermal energy and subsequently 
prompt the Fenton reaction. We are currently planning to investigate the degradation mechanisms of MB and ORII in detail. Moreover, the removal percentage of TC in MB and ORII was greater at higher temperature. These results suggest that the Fenton reaction could cause the decomposition of $\mathrm{MB}$ and ORII at a wide temperature range. However, this treatment could not perfectly remove the total organic carbon produced from MB and ORII decomposition. Similar trends were observed in the previous study. ${ }^{1)}$

Effects of Sulfuric Acid, Hydrochloric Acid, and Nitric Acid on Adjustment of Solution pH Previous studies have reported that sulfuric acid and sodium hydroxide are used only for the adjustment of solution $\mathrm{pH}$ in the Fenton reaction. ${ }^{5,6,10,14,15)}$ The main chemical cost of Fenton's reagent is the cost of the $\mathrm{H}_{2} \mathrm{O}_{2}$ and other compounds (the price of $\mathrm{H}_{2} \mathrm{O}_{2}$ is 1150-Japanese yen $/ 500 \mathrm{~mL}, \mathrm{HCl}$ is 850 -Japanese yen $/ 500 \mathrm{~mL}$, $\mathrm{HNO}_{3}$ is 1300 -Japanese yen $/ 500 \mathrm{~mL}$, and $\mathrm{H}_{2} \mathrm{SO}_{4}$ is 800 -Japanese yen $/ 500 \mathrm{~mL}$ ), so it is important to optimize the amount of Fenton's reagents in the Fenton's oxidation technology. That is, there is need to develop low cost oxidation technology. In this study, we focused on the adjustment reagent of solution $\mathrm{pH}$. Dutta et al. reported the effect of electrolytes on degradation of MB. ${ }^{5)}$ The presence of halide salts at the same concentration level substantially decreased the rate and extent of degradation, whereas the lowering in the extent of degradation was much less pronounced for sulfate salts, suggesting that it is important to select the most useful reagent for efficient degradation of $\mathrm{MB}$ and ORII by the Fenton reaction. We selected several acidic solutions in this study. Figure 4 shows the effects of the acidic solutions on the decoloration of the dyes. The decoloration percentage of both MB and ORII was in the order $\mathrm{H}_{2} \mathrm{SO}_{4}<\mathrm{HCl}<\mathrm{HNO}_{3}$. The decoloration was not positively correlated with $\mathrm{p} K_{\mathrm{a}}\left(\mathrm{HCl}(-8.0)<\mathrm{H}_{2} \mathrm{SO}_{4}(-3.0)<\mathrm{HNO}_{3}\right.$ $(-1.4))$ neither was there a correlation to the oxidative effect $\left(\mathrm{HCl}<\mathrm{H}_{2} \mathrm{SO}_{4}<\mathrm{HNO}_{3}\right)$ of the reagents. The Fenton reaction followed Eqs. 2 and 3. The stability of complex formation with $\mathrm{Fe}^{3+}$ was in the order $\mathrm{NO}_{3}^{-}<\mathrm{Cl}^{-}<\mathrm{SO}_{4}^{2-}$, ${ }^{16)}$ which suggests that the $\mathrm{Fe}^{3+}$ generated in the Fenton reaction reacted with each anion and that subsequently complex formation occurred and the Fenton like reaction was inhibited (the reactivity of $\mathrm{Fe}^{3+}$ was lower). These results indicate that the decoloration percentage using $\mathrm{HCl}$ and $\mathrm{HNO}_{3}$ was greater than that using $\mathrm{H}_{2} \mathrm{SO}_{4}$, which is often used in the Fenton reaction. The difference was approximately 4.3-5.6 and 1.7-5.6 times for $\mathrm{HCl}$ and $\mathrm{HNO}_{3}$ in $\mathrm{MB}$ decoloration and approximately 3.2-3.6 and 4.6-7.2 times for $\mathrm{HCl}$ and $\mathrm{HNO}_{3}$ in ORII decoloration, respectively. As mentioned previously, the cost of $\mathrm{HCl}$ and $\mathrm{HNO}_{3}$ used in this study is 1.06 and 1.63 times higher compared to that of $\mathrm{H}_{2} \mathrm{SO}_{4}$. However, the decoloration capacity of $\mathrm{MB}$ and ORII using $\mathrm{HCl}$ and $\mathrm{HNO}_{3}$ is over 1.06 and 1.63 times higher when compared to $\mathrm{H}_{2} \mathrm{SO}_{4}$ (Fig. 4(C)). This finding has not been reported previously and is a novel result pertaining to the homogeneous Fenton reaction process. However, we still need to evaluate the degradation mechanism of MB and ORII when using $\mathrm{HCl}$ and $\mathrm{HNO}_{3}$ in the Fenton reaction in detail.

\section{Conclusion}

We evaluated the degradation of MB and ORII by the homogeneous Fenton reaction. The optimal $\mathrm{pH}$ for degradation of MB and ORII is 2.5. The decoloration and removal of TC increased with increasing concentration of Fenton's reagents and temperature, which indicates that the thermal energy was increased and subsequently prompted the Fenton reaction. Finally, we found that the decoloration of MB and ORII was greater in the Fenton reaction with $\mathrm{HCl}$ and $\mathrm{HNO}_{3}$ than in the reaction with $\mathrm{H}_{2} \mathrm{SO}_{4}$. These results indicate that the stability of complex formation with $\mathrm{Fe}^{3+}$ increases in the order $\mathrm{NO}_{3}^{-}<\mathrm{Cl}^{-}<\mathrm{SO}_{4}^{2-}$. Therefore, the $\mathrm{Fe}^{3+}$ generated in the Fenton reaction reacted with each anion and subsequently complex formation occurred and the Fenton like reaction was inhibited. This study elucidated an efficient technology for degradation of $\mathrm{MB}$ and $\mathrm{ORII}$ by Fenton reaction with $\mathrm{HCl}$ and $\mathrm{HNO}_{3}$.

Acknowledgments Ministry of Education, Culture, Sports, Science and Technology (MEXT)-supported Program for the Strategic Research Foundation at Private Universities, 2014-2018 (S1411037).

Conflict of Interest The authors declare no conflict of interest.

\section{References}

1) Ramirez J. H., Maldonado-Hódar F. J., Pérez-Cadenas A. F., Moreno-Castilla C., Costa C. A., Madeira L. M., Appl. Catal. B, 75, 312-323 (2007)

2) Venkataraman K., "The Chemistry of Synthetic Dyes," Vol. II, Academic Press, New York, 1952.

3) Zheng J., Gao Z., He H., Yang S., Sun C., Chemosphere, 150, 40-48 (2016).

4) Clarke C. E., Johnson K. L., Appl. Catal. B, 101, 13-20 (2010).

5) Dutta K., Mukhopadhyay S., Bhattacharjee S., Chaudhuri B., J. Hazard. Mater., 84, 57-71 (2001).

6) Gao M., Zhang D., Li W., Chang J., Lin Q., Xu D., Ma H., J. Taiwan Inst. Chem. Eng., 67, 355-361 (2016).

7) Hou C. Y., Zhang Q. H., Li Y. Y., Wang H., J. Hazard. Mater., 205-206, 229-235 (2012)

8) Babuponnusami A., Muthukumar K., J. Environ. Chem. Eng., 2, 557-572 (2014).

9) Kuwahata H., Kezuka S., Proc. Sch. Eng. Tokai Univ., 54, 9-14 (2014).

10) Li H., Li Y., Xiang L., Huang Q., Qiu J., Zhang H., Sivaiah M. V., Baron F., Barrault J., Petit S., Valange S., J. Hazard. Mater., 287, 32-41 (2015).

11) Hammami S., Bellakhal N., Oturan N., Oturan M. A., Dachraoui M., Chemosphere, 73, 678-684 (2008)

12) Xu X. R., Li X. Y., Li X. Z., Li H. B., Separ. Purif. Tech., 68 , 261-266 (2009).

13) Yang S., Tahara M., Maekawa M., FIBER, 66, 51-55 (2010).

14) Tian S. H., Tu Y. T., Chen D. S., Chen X., Xiong Y., Chem. Eng. J., 169, 31-37 (2011)

15) Tian S., Zhang J., Chen J., Kong L., Lu J., Ding F., Xiong Y., Ind. Eng. Res., 52, 13333-13341 (2013).

16) Bjerrum J., Schwarzenbach G., Sillen L., "Stability Constants of Metal Ion Complexes, Part II: Inorganic Ligands," Chemical Society, London, 1958. 